
2 Research Square
Preprints are preliminary reports that have not undergone peer review.
They should not be considered conclusive, used to inform clinical practice, or referenced by the media as validated information.

\title{
Value of Variation of End-Tidal Carbon Dioxide for Predicting Fluid Responsiveness During the Passive Leg Raising Test in Patients with Mechanical Ventilation: A Systematic Review and Meta-Analysis
}

\author{
Haijun Huang \\ The First Affiliated Hospital of Zhejiang Chinese Medical University \\ Chenxia Wu \\ The first affiliated hospital of zhejiang chinese mecical university \\ Qinkang Shen \\ The first affliated hospital of zhejiang chinese medical university

\section{Yixin Fang} \\ The first affiliated hospital of zhejiang chinese medical university \\ Hua Xu ( $\nabla$ hz_xuhua@163.com) \\ The first affiliated hospital of zhejiang chinese medical university
}

Research

Keywords: Fluid responsiveness, end-tidal carbon dioxide, mechanical ventilation, meta-analysis

Posted Date: November 18th, 2021

DOI: https://doi.org/10.21203/rs.3.rs-1069765/v1

License: (c) (i) This work is licensed under a Creative Commons Attribution 4.0 International License. Read Full License

Version of Record: A version of this preprint was published at Critical Care on January 14th, 2022. See the published version at https://doi.org/10.1186/s13054-022-03890-9. 


\section{Abstract}

Background: The variation of end-tidal carbon dioxide( $\triangle \mathrm{EtCO})$ has have been extensively studied with respect to its value in predicting fluid responsiveness, but the results are conflicting. This meta-analysis aimed to explore the value of $\triangle \mathrm{EtCO} 2$ for predicting fluid responsiveness during the passive leg raising(PLR) test in patients with mechanical ventilation.

Methods: PubMed, Embase, and Cochrane Central Register of Controlled Trials were searched up to November 2021. The diagnostic odds ratio (DOR), sensitivity, and specificity were calculated. The summary receiver operating characteristic curve was estimated, and the area under the curve (AUROC) was calculated. We performed meta-regression analysis for heterogeneity exploration and sensitivity analysis for the publication bias.

Results: Overall, 298 patients were included in this review, of whom $149(50 \%)$ were fluid responsive. The cutoff values of $\Delta$ EtCO2 varied across studies, ranging from $5 \%$ to $5.8 \%$ or absolute increase $2 \mathrm{mmHg}$. Heterogeneity between studies was assessed with an overall $Q=4.098, P=51 \%$, and $P=0.064$. The pooled sensitivity and specificity for the overall population were 0.79 (95\% Cl: $0.72-0.85)$ and 0.90 (95\% Cl: $0.77-0.96)$, respectively. The DOR was 35 (95\% Cl: 12-107) (Fig. 4). The pooled AUROC was 0.81 (95\% Cl: 0.77-0.84). On meta-regression analysis, the number of patients was sources of heterogeneity. The sensitivity analysis showed that the pooled DOR ranged from 21 to 140 and the pooled AUC ranged from 0.92 to 0.96 when one study was omitted.

Conclusions: This study was the first meta-analysis to evaluate the diagnostic accuracy of $\triangle \mathrm{EtCO} 2$ in predicting fluid responsiveness during PLR test in patients with mechanical ventilation. This study confirmed that the $\triangle \mathrm{EtCO} 2$ performed well in predicting fluid responsiveness in patients with mechanical ventilation.

\section{Introduction}

Fluid resuscitation is recommended and widely used as the first-line resuscitative therapy for all patients presenting with acute circulatory failure[1]. Although the volume status of a shocked patient is recovered, evidence suggests that inappropriate administration of fluids has deleterious effects such as volume overload, systemic and pulmonary edema, and limitation of oxygen diffusion to tissues, thereby leading to increased tissue hypoxia [2-4]. Therefore, it is important to obtain reliable information about fluid responsiveness in patients having a circulatory failure in the intensive care unit. However, clinicians are often faced with inaccurate, nonspecific information to guide their treatment.

Previous studies have shown that some parameters may be related to volume status. The traditional static parameters, such as intrathoracic blood volume index, pulmonary wedge pressure, and central venous pressure, have been proved not related to patient volume status $[5,6]$. Hemodynamic parameters, such as pulse pressure variation and stroke volume variation, may better predict fluid responsiveness. However, the evaluation of these parameters requires invasive procedures and special monitoring equipment, limiting their clinical application [7].

End-tidal carbon dioxide (EtCO2) is the partial pressure of carbon dioxide (PCO2) in the exhaled air measured at the end of expiration. Measurement of EtCO2 using capnography provides a noninvasive estimate of cardiac output and organ perfusion during cardiac arrest and can therefore be used to monitor the quality of cardiopulmonary resuscitation and predict return of spontaneous circulation[8-10]. In recent years, the variation of EtCO2 $(\triangle \mathrm{EtCO} 2)$ during passive leg raising(PLR) test or fluid challenge has been considered as a tool to help guide fluid resuscitation[11-17]. Physiologically, EtCO2 depends on three variables: tissue $\mathrm{CO} 2$ production, pulmonary blood flow (i.e. cardiac output), and alveolar ventilation[18]. Thus, EtCO2 may accurately reflect cardiac output when ventilator parameters and $\mathrm{CO} 2$ production are constant. This correlation has been tested in experimental[19] and clinical[20] studies. Therefore, it is theoretically possible to assess fluid responsiveness after PLR test or volume expansion according to $\triangle$ EtCO2 if there is no major change in heart rate.

In this systematic review and meta-analysis, the test characteristics of $\triangle$ EtCO2 were summarized as a predictor of fluid responsiveness during PLR test in patients with mechanical ventilation to elucidate their diagnostic performance further and provide information for the early detection of fluid responders.

\section{Materials And Methods}

This meta-analysis was conducted according to the Preferred Reporting Items for Systematic Reviews and Meta-analyses guidance [21].

\section{Registration and protocol}

This meta-analysis was registered on PROSPERO(CRD42021284241)

\section{Search strategy}

Relevant studies up to November 2021 were searched in the PubMed, Embase, and Cochrane Library databases with the following terms and their combinations: "fluid therapy OR fluid responsive OR volume responsive," "end tidal carbon dioxide OR end-tidal carbon dioxide OR EtCO ${ }_{2}$ " and "mechanical ventilation OR ventilated." All scanned abstracts, studies, and citations were reviewed. Moreover, references of the retrieved manuscripts were also manually cross-searched for further relevant publications.

\section{Selection criteria}

The inclusion criteria were as follows: (1) studies on patients receiving mechanical ventilation;(2) studies with PLR-induced increase in EtCO2 as the index test; (3) studies with a gold reference standard for the diagnosis of fluid responsiveness; (4) studies published with full-text in any language; (5) studies providing 
sufficient data for constructing 2-by-2 tables, including true positive (TP), false positive (FP), true negative (TN), and false negative (FN). The exclusion criteria were as follows: (1) studies that used the same population or overlapping database and (2) studies on animal models.

\section{Data extraction and quality assessment}

All the available data were extracted from each study by two investigators independently according to the aforementioned inclusion criteria, and any differences were resolved by discussion with a third investigator. The following data were collected from each study: (1) basic characteristics of studies, including first author name, publication year, country where the research was performed, selected patients, gender, mean age, number of patients, tidal volume, index test device for the EtCO2, reference standard measurement, reference standard threshold, and reference standard device; (2) diagnostic performance, including cutoff value, sensitivity, specificity, area under the receiver operator characteristic curve (AUROC), TP, FP, FN, and TN. The quality of included studies was scored independently by two reviewers using the revised Quality Assessment of Diagnostic Accuracy Studies (QUADAS-2) criteria [22]. The quality of studies was assessed using RevMan 5.4 .

\section{Statistical analysis}

All analyses were performed using the Stata 16.0 software (Stata Corp., College Station, TX, USA). The bivariate meta-analysis model was employed to summarize sensitivity, specificity, positive likelihood ratio, negative likelihood ratio, and diagnostic odds ratio (DOR) [23, 24]. The sensitivity and specificity of each included study were used to plot the summary receiver operator characteristic (SROC) curve and calculate the area under the SROC curve (AUC). Diagnostic power was good, moderate, and poor if the AUC was more than 0.8 , between 0.7 and 0.8 , and less than 0.7 , respectively[25]. As publication bias is a concern for meta-analyses, the Deeks' funnel plot asymmetry test was used, with $P \otimes 0.10$ indicating statistical significance [26].If publication bias was present, a sensitivity analysis was performed to explore why.

Spearman's correlation coefficient between the logit of sensitivity and logit of 1-specificity was calculated to determine any threshold effect; A strong positive correlation would suggest threshold effect[27]. The between-study heterogeneity was evaluated using $Q$ test and $P^{2}$ statistics. A $P$ value less than 0.10 for the $Q$ test or $P^{2}$ value $\geq 50 \%$ indicated substantial heterogeneity. A fixed effects model was used if no heterogeneity was observed. A random effects model was selected if significant heterogeneity was observed. Possible sources of heterogeneity were explored through a meta-regression analysis.

\section{Results}

\section{Characteristics of the studies}

This meta-analysis yielded 279 primary studies after the initial independent review, comprising 278 published studies identified through electronic database searches and 1 published study identified through a manual search. Figure 1 shows the study selection process. A total of 7 records were initially excluded due to duplicate records; 259 records were excluded due to the source not related to the research topic or being conference abstract; and 7 records were excluded because they did the fluid responsiveness test by different dose fluid challenge. Finally, six studies[15, 16, 28-31] fulfilled all the inclusion criteria and were considered for analysis. They are all prospective single center studies, the main characteristics of the eligible studies are shown in Table 1 . The quality of the included studies was assessed using QUADAS-2 available in Fig. 2. 
Table 1

Characteristics of the studies included in this meta-analysis

\begin{tabular}{|c|c|c|c|c|c|c|c|c|c|}
\hline $\begin{array}{l}\text { First author/ } \\
\text { Year of } \\
\text { publication }\end{array}$ & Country & patients & $\begin{array}{l}\text { Gender } \\
(\mathrm{M} / \mathrm{f})\end{array}$ & $\begin{array}{l}\text { Age } \\
\text { (year) } \\
\text { Mean } \\
\pm \text { SD }\end{array}$ & Cases & $\begin{array}{l}\text { Tidal } \\
\text { Volume } \\
(\mathrm{mL} / \mathrm{kg})\end{array}$ & $\begin{array}{l}\text { Index } \\
\text { test } \\
\text { device }\end{array}$ & $\begin{array}{l}\text { Reference } \\
\text { standard } \\
\text { measurement }\end{array}$ & $\begin{array}{l}\text { Reference } \\
\text { standard } \\
\text { Threshold } \\
\text { (\%) }\end{array}$ \\
\hline Monge/ 2012[16] & Spanish & $\begin{array}{l}\text { patients with } \\
\text { controlled } \\
\text { mechanical } \\
\text { ventilation } \\
\text { and acute } \\
\text { circulatory } \\
\text { failure }\end{array}$ & $16 / 21$ & $64 \pm 13$ & 37 & $8.1 \pm 1.2$ & $\begin{array}{l}\text { Side } \\
\text { stream } \\
\text { infrared } \\
\text { gas } \\
\text { analyzer }\end{array}$ & $\mathrm{CO}$ & $\geq 15$ \\
\hline Monnet/2013[15] & France & $\begin{array}{l}\text { Patients } \\
\text { ventilated in } \\
\text { the control } \\
\text { assisted } \\
\text { mode with no } \\
\text { inspiratory } \\
\text { effort and } \\
\text { hemodynamic } \\
\text { instability }\end{array}$ & NA & $60 \pm 14$ & 40 & $6.4 \pm 0.8$ & $\begin{array}{l}\text { Side } \\
\text { stream } \\
\text { infrared } \\
\text { gas } \\
\text { analyzer }\end{array}$ & $\mathrm{Cl}$ & $\geq 15$ \\
\hline Zang/2013 [28] & China & $\begin{array}{l}\text { patients with } \\
\text { controlled } \\
\text { mechanical } \\
\text { ventilation } \\
\text { and sepsis } \\
\text { shock }\end{array}$ & $22 / 20$ & $\begin{array}{l}\text { Responder: } 56.9 \pm 16.6 \\
\text { Nonresponder: } 57.7 \pm 12.3\end{array}$ & 42 & $\begin{array}{l}\text { Responder: } \\
7.5 \pm 3.6 \\
\text { Nonresponder: } \\
7.7 \pm 2.3\end{array}$ & $\begin{array}{l}\text { Side } \\
\text { stream } \\
\text { infrared } \\
\text { gas } \\
\text { analyzer }\end{array}$ & $\mathrm{Cl}$ & $\geq 15$ \\
\hline Wang/2015 [29] & China & $\begin{array}{l}\text { patients with } \\
\text { controlled } \\
\text { mechanical } \\
\text { ventilation } \\
\text { and sepsis } \\
\text { shock }\end{array}$ & $24 / 24$ & $\begin{array}{l}\text { Responder: } 52.7 \pm 29.4 \\
\text { Nonresponder: } 56.7 \pm \\
26.2\end{array}$ & 48 & NA & $\begin{array}{l}\text { Side } \\
\text { stream } \\
\text { infrared } \\
\text { gas } \\
\text { analyzer }\end{array}$ & $\mathrm{Cl}$ & $\bigotimes 10$ \\
\hline Toupin/2016 [30] & Canada & $\begin{array}{l}\text { patients } \\
\text { receiving } \\
\text { mechanical } \\
\text { ventilation } \\
\text { and } \\
\text { undergoing } \\
\text { cardiac or } \\
\text { ascending } \\
\text { aortic surgery }\end{array}$ & $62 / 28$ & $\begin{array}{l}\text { Responder: } \\
68 \pm 10 \\
\text { Nonresponder: } 65 \pm 10\end{array}$ & 90 & $6-8$ & $\begin{array}{l}\text { Side } \\
\text { stream } \\
\text { infrared } \\
\text { gas } \\
\text { analyzer }\end{array}$ & $\mathrm{Cl}$ & $\geq 15$ \\
\hline Yao /2016 [31] & China & $\begin{array}{l}\text { patients with } \\
\text { controlled } \\
\text { mechanical } \\
\text { ventilation } \\
\text { and shock } \\
\text { post-cardiac } \\
\text { surgery }\end{array}$ & $27 / 14$ & $\begin{array}{l}\text { Responder: } \\
55.4 \pm 9.9 \\
\text { Nonresponder:58.5 } \pm 9.3\end{array}$ & 41 & $8-10$ & NA & $\mathrm{Cl}$ & $\geq 15$ \\
\hline
\end{tabular}

\section{Quantitative synthesis}

Study data and individual diagnostic estimates are summarized in Table 2. Overall, 298 patients were included in this review, of whom 149 (50\%) were fluid responsive. The cutoff values of $\triangle \mathrm{EtCO} 2$ varied across studies, ranging from $5-5.8 \%$ or absolute increase $2 \mathrm{mmHg}$. The AUROC of individual studies ranged from 0.80 to 0.94 . Heterogeneity between studies was assessed with an overall $Q=4.098, R=51 \%$, and $P=0.064$, indicated substantial heterogeneity. Spearman's correlation coefficient was $-0.6(p=0.28)$, indicating no threshold effect. The pooled sensitivity and specificity for the overall population were 0.79 (95\% Cl: $0.72-0.85)$ and 0.90 (95\% Cl: 0.77-0.96), respectively (Fig. 3). The pooled positive likelihood ratio and negative likelihood ratio were 8.2 (95\%Cl: 3.220.5) and 0.23 (95\%Cl: 0.16-0.32), respectively. The DOR was 35 (95\% Cl: 12-107) (Fig. 4). The pooled AUROC was 0.81 (95\% Cl: 0.77-0.84) (Fig. 5). 
Table 2

Summary of results of the studies included in this meta-analysis

\begin{tabular}{|c|c|c|c|c|c|c|c|c|c|}
\hline \multirow{2}{*}{$\begin{array}{l}\text { First author/ } \\
\text { Year of } \\
\text { publication }\end{array}$} & \multirow{2}{*}{$\begin{array}{l}\text { Sample } \\
\text { size }\end{array}$} & \multirow[t]{2}{*}{$\begin{array}{l}\text { Cutoff value (increase in percentage or } \\
\text { absolute value) }\end{array}$} & \multicolumn{4}{|c|}{$\begin{array}{l}\text { Subject numbers could be } \\
\text { calculated }\end{array}$} & \multirow[t]{2}{*}{$\begin{array}{l}\text { Sensitivity } \\
\text { (\%) }\end{array}$} & \multirow[t]{2}{*}{$\begin{array}{l}\text { Specificity } \\
(\%)\end{array}$} & \multirow[t]{2}{*}{$\begin{array}{l}\text { AUROC } \\
(95 \% \mathrm{Cl})\end{array}$} \\
\hline & & & TP & FP & FN & TN & & & \\
\hline Monge/ 2012[16] & 37 & $5 \%$ & 19 & 1 & 2 & 19 & 90.5 & 93.7 & $\begin{array}{l}0.94(0.82- \\
0.99)\end{array}$ \\
\hline Monnet/2013[15] & 40 & $5 \%$ & 15 & 0 & 6 & 15 & 71 & 100 & $\begin{array}{l}0.93(0.81- \\
0.99)\end{array}$ \\
\hline Zang/2013 [28] & 42 & $5 \%$ & 21 & 2 & 3 & 21 & 88 & 88.2 & $\begin{array}{l}0.90(0.775- \\
1.0)\end{array}$ \\
\hline Wang/2015 [29] & 48 & $5 \%$ & 26 & 1 & 8 & 26 & 75.8 & 93.4 & $\begin{array}{l}0.849 \\
(0.739-0.93\end{array}$ \\
\hline Toupin/2016 [30] & 90 & $2 \mathrm{mmHg}$ & 21 & 19 & 7 & 21 & 75 & 70 & $\begin{array}{l}0.80(0.70- \\
0.90)\end{array}$ \\
\hline Yao /2016 [31] & 41 & $5.8 \%$ & 16 & 2 & 5 & 16 & 76.2 & 90 & $\begin{array}{l}0.875(0.769 \\
0.981)\end{array}$ \\
\hline
\end{tabular}

\section{Meta-regression analysis results}

Meta-regression analyses were performed to investigate the potential causes of heterogeneity using several covariates, as follows: (1)location (China vs. countries other than China), (2)number of patients ( $\mathbb{4} 45 \mathrm{vs} .<45),(3)$ reference standard measurement (CO vs. $\mathrm{Cl}$ ), and (4) reference standard device(TEE vs. $\mathrm{PiCCO}$ ). The results of the meta-regression analyses (Fig. 6) showed that the significant sources of heterogeneity in sensitivity and specificity were the number of patients.

\section{Publication bias and Sensitivity analysis}

The publication bias of the studies was assessed using the Deeks' funnel plot asymmetry test. The slope coefficient of the six studies was associated with a $P$ value of 0.01 (Fig. 7). The aforementioned results indicated significant publication bias. The sensitivity analysis(Fig. 8) showed that excluding Toupin's study[30] negated the publication bias $(p=0.36)$. The sensitivity analysis also showed that the pooled DOR ranged from 21 to 140 and the pooled AUC ranged from 0.92 to 0.96 when one study was omitted.

\section{Discussion}

The correct evaluation of intravascular volume and proper maintenance of cardiac preload can improve the prognosis of critically ill patients. Static variables could not predict fluid responsiveness[32-35]. However, dynamic indicators of fluid responsiveness, which are based on cardiopulmonary interactions in patients receiving mechanical ventilation, have been shown to be predictive [36-40]. The $\Delta \mathrm{EtCO}$, has been extensively studied with respect to its value in predicting fluid responsiveness, but the results are conflicting[11-16, 28-31, 41-43]. To the best of our knowledge, this is the first systematic review and meta-analysis to explore the diagnostic accuracy of $\Delta \mathrm{EtCO}_{2}$ in predicting fluid responsiveness during PLR test in patients with mechanical ventilation. The results confirmed that, overall, the $\triangle \mathrm{EtCO}_{2}$ performed well in predicting fluid responsiveness in patients with mechanical ventilation during PLR test, with a pooled AUROC of 0.81 (95\% Cl: $0.77-0.84)$, a pooled specificity and sensitivity of 0.90 (95\% Cl: $0.77-0.96)$ and 0.79 (95\% Cl: $0.72-0.85)$. These findings are clinically relevant because capnography was widely available for critically ill patients, and $\Delta \mathrm{EtCO}_{2}$ values can be obtained immediately in the emergency or critical care setting.

The PLR test provides a dynamic assessment of preload dependence inducing a transient and reversible increase in cardiac preload. This test has been demonstrated to predict fluid responsiveness in many studies over a wide population, including clinical situations in which other parameters of fluid responsiveness have failed, such as patients with cardiac arrhythmias or with spontaneous breathing[44, 45]. However the PLR must be interpreted in conjunction with changes in $\mathrm{CO}$, velocity time integral, aortic blood flow velocity, carotid artery flow time[46],the need for measuring such index usually limits the widespread application of this test to a specific group of patients requiring expensive, burdensome or invasive hemodynamic monitoring systems. EtCO2 can be easily determined with continuous waveform-capnography devices that are generally available in the clinical. In the present study, we showed that fluid responsiveness can be assessed using EtCO2 monitoring and PLR test. This provides a clinically useful way to predict fluid responsiveness using readily available diagnostic tools such as a PLR maneuver and EtCO2 measurement by capnography.

The present systematic review and meta-analysis had some limitations. First, this analysis included only six studies with a relatively small sample size even pooled analysis there are only 298 patients were included in this review. Therefore, the power and precision of the results were limited. Second, the quality assessment showed a high risk of bias in the index test. This bias might have restricted the interpretation of the true diagnostic efficacy of $\Delta$ EtCO2 value in predicting fluid responsiveness. Third, publication bias was observed among studies. We performed a sensitivity analysis and found that the pooled DOR 
ranged from 21 to 140 and the pooled AUC ranged from 0.92 to 0.96 . This indicates that the results were stable despite the presence of publication bias. Finally, since more detailed individual patient data were not available, a more comprehensive analysis of diagnostic effect could not be conducted.

\section{Conclusions}

This was the first meta-analysis to evaluate the diagnostic accuracy of $\Delta \mathrm{EtCO}_{2}$ in predicting fluid responsiveness in patients with mechanical ventilation during PLR test. The study confirmed that the $\triangle \mathrm{EtCO}_{2}$ performed well in predicting fluid responsiveness in patients with mechanical ventilation during PLR test. Further studies with a larger data set and well-designed models are required to confirm the diagnostic accuracy and utility of EtCO2 in predicting fluid responsiveness in patients with mechanical ventilation during PLR test.

\section{Abbreviations}

\section{$\triangle \mathrm{EtCO} 2$}

Variation of end-tidal carbon dioxide

PLR

Passive leg raising

EtCO2

End-tidal carbon dioxide

DOR

Diagnostic odds ratio

$\mathrm{Cl}$

Confidence interval

TP

True positive

FP

False positive

TN

True negative

FN

False negative

AUROC

Aarea under the receiver operator characteristic curve

QUADAS-2

Quality Assessment of Diagnostic Accuracy Studies

SROC

Summary receiver operator characteristic

AUC

Area under the SROC curve

\section{Declarations}

\section{Ethics approval and consent to participate}

Not applicable.

\section{Consent for publication}

Not applicable.

\section{Availability of data and material}

The datasets used and/or analysed during the current study are available from the corresponding author on reasonable request.

\section{Competing interests}

All authors declare that they have no any conflict of interests.

\section{Funding}

This work was supported by Zhejiang Traditional Chinese Medicine Science and Technology Project(NO. 2020ZA046)

\section{Authors' contributions}


Haijun Huang and Hua Xu carried out the studies, participated in collecting data, and drafted the manuscript. Chenxia Wu and Qinkang Shen performed the statistical analysis and participated in its design. Yixin Fang helped to draft the manuscript. All authors read and approved the final manuscript.

\section{Acknowledgements}

None.

\section{References}

1. Byrne L, Van Haren F: Fluid resuscitation in human sepsis: Time to rewrite history? Annals of intensive care 2017, 7(1):4.

2. Pinsky MR, Brophy P, Padilla J, Paganini E, Pannu N: Fluid and volume monitoring. The International journal of artificial organs 2008, 31(2):111-126.

3. Wiedemann HP, Wheeler AP, Bernard GR, Thompson BT, Hayden D, deBoisblanc B, Connors AF, Jr., Hite RD, Harabin AL: Comparison of two fluidmanagement strategies in acute lung injury. The New England journal of medicine 2006, 354(24):2564-2575.

4. Acheampong A, Vincent JL: A positive fluid balance is an independent prognostic factor in patients with sepsis. Critical care (London, England) 2015, 19:251.

5. Bindels AJ, van der Hoeven JG, Graafland AD, de Koning J, Meinders AE: Relationships between volume and pressure measurements and stroke volume in critically ill patients. Critical care (London, England) 2000, 4(3):193-199.

6. Hu B, Xiang H, Liang H, Yu L, Xu T, Yang JH, Du ZH, Li JG: Assessment effect of central venous pressure in fluid resuscitation in the patients with shock: a multi-center retrospective research. Chinese medical journal 2013, 126(10):1844-1849.

7. Pinsky MR: Functional haemodynamic monitoring. Current opinion in critical care 2014, 20(3):288-293.

8. Hartmann SM, Farris RW, Di Gennaro JL, Roberts JS: Systematic Review and Meta-Analysis of End-Tidal Carbon Dioxide Values Associated With Retum of Spontaneous Circulation During Cardiopulmonary Resuscitation. Journal of intensive care medicine 2015, 30(7):426-435

9. Sandroni C, De Santis P, D'Arrigo S: Capnography during cardiac arrest. Resuscitation 2018, 132:73-77.

10. Touma O, Davies M: The prognostic value of end tidal carbon dioxide during cardiac arrest: a systematic review. Resuscitation 2013, 84(11):1470-1479.

11. de Courson H, Chauvet J, Le Gall L, Georges D, Boyer P, Verchere E, Nouette-Gaulain K, Biais M: Utility of changes in end-tidal carbon dioxide after volume expansion to assess fluid responsiveness in the operating room: a prospective observational study. British journal of anaesthesia 2020, $125(5)$ :672-679.

12. Lakhal K, Nay MA, Kamel T, Lortat-Jacob B, Ehrmann S, Rozec B, Boulain T: Change in end-tidal carbon dioxide outperforms other surrogates for change in cardiac output during fluid challenge. British journal of anaesthesia 2017, 118(3):355-362.

13. Jacquet-Lagrèze $\mathrm{M}$, Baudin F, David JS, Fellahi J-L, Hu PB, Lilot M, Piriou V: End-tidal carbon dioxide variation after a 100-and a 500-ml fluid challenge to assess fluid responsiveness. Annals of intensive care 2016, 6(1).

14. Young A, Marik PE, Sibole S, Grooms D, Levitov A: Changes in end-tidal carbon dioxide and volumetric carbon dioxide as predictors of volume responsiveness in hemodynamically unstable patients. Journal of cardiothoracic and vascular anesthesia 2013, 27(4):681-684.

15. Monnet X, Bataille A, Magalhaes E, Barrois J, Le Corre M, Gosset C, Guerin L, Richard C, Teboul JL: End-tidal carbon dioxide is better than arterial pressure for predicting volume responsiveness by the passive leg raising test. Intensive care medicine 2013, 39(1):93-100.

16. Monge García MI, Gil Cano A, Gracia Romero M, Monterroso Pintado R, Pérez Madueño V, Díaz Monrové JC: Non-invasive assessment of fluid responsiveness by changes in partial end-tidal $\mathrm{CO} 2$ pressure during a passive leg-raising maneuver. Annals of intensive care $2012,2: 9$.

17. Güney Pınar S, Pekdemir M, Özturan I U, Doğan N, Yaka E, Yılmaz S, Karadaş A, Ferek Emir D: Assessment of end-tidal carbon dioxide and vena cava collapsibility in volume responsiveness in spontaneously breathing patients. Medizinische Klinik, Intensivmedizin und Notfallmedizin 2020.

18. Anderson CT, Breen PH: Carbon dioxide kinetics and capnography during critical care. Critical care (London, England) 2000, 4(4):207-215.

19. Jin X, Weil MH, Tang W, Povoas H, Pernat A, Xie J, Bisera J: End-tidal carbon dioxide as a noninvasive indicator of cardiac index during circulatory shock. Critical care medicine 2000, 48(7):2415-2419.

20. Shibutani K, Muraoka M, Shirasaki S, Kubal K, Sanchala VT, Gupte P: Do changes in end-tidal PCO2 quantitatively reflect changes in cardiac output? Anesthesia and analgesia 1994, 79(5):829-833.

21. Moher D, Liberati A, Tetzlaff J, Altman DG: Preferred reporting items for systematic reviews and meta-analyses: the PRISMA statement. Annals of internal medicine 2009, 151(4):264-269, w264.

22. Whiting PF, Rutjes AW, Westwood ME, Mallett S, Deeks JJ, Reitsma JB, Leeflang MM, Sterne JA, Bossuyt PM: QUADAS-2: a revised tool for the quality assessment of diagnostic accuracy studies. Annals of internal medicine 2011, 155(8):529-536.

23. Deeks JJ: Systematic reviews in health care: Systematic reviews of evaluations of diagnostic and screening tests. BMJ (Clinical research ed) 2001, 323(7305):157-162.

24. Glas AS, Lijmer JG, Prins MH, Bonsel GJ, Bossuyt PM: The diagnostic odds ratio: a single indicator of test performance. Journal of clinical epidemiology 2003, 56(11):1129-1135.

25. Mandrekar JN: Receiver operating characteristic curve in diagnostic test assessment. Journal of thoracic oncology: official publication of the International Association for the Study of Lung Cancer 2010, 5. 
26. Deeks JJ, Macaskill P, Irwig L: The performance of tests of publication bias and other sample size effects in systematic reviews of diagnostic test accuracy was assessed. Journal of clinical epidemiology 2005, 58(9):882-893.

27. Zamora J, Abraira V, Muriel A, Khan K, Coomarasamy A: Meta-DiSc: a software for meta-analysis of test accuracy data. $B M C$ medical research methodology 2006, 6:31.

28. Zang ZD, Yan J, Xu HY, Liang FM, Yang T, Wang DP, Gao F: The value of changes in end-tidal carbon dioxide pressure induced by passive leg raising test in predicting fluid responsiveness in mechanically ventilated patients with septic shock. Zhonghua nei ke za zhi 2013, 52(8):646-650.

29. Xiao-ting W, Hua Z, Da-wei L, Hong-min Z, Huai-wu H, Yun L, Wen-zhao C: Changes in end-tidal CO2 could predict fluid responsiveness in the passive leg raising test but not in the mini-fluid challenge test: A prospective and observational study. Journal of critical care 2015, 30(5):1061-1066.

30. Toupin F, Clairoux A, Deschamps A, Lebon JS, Lamarche Y, Lambert J, Fortier A, Denault AY: Assessment of fluid responsiveness with end-tidal carbon dioxide using a simplified passive leg raising maneuver: a prospective observational study. Canadian journal of anaesthesia = Journal canadien d'anesthesie 2016, 63(9):1033-1041.

31. Yao T, Wu W, Zheng X, Fang Q: The value of end-tidal carbon dioxide partial pressure combined passive leg raising test on volume responsiveness assessment in shocked patients post cardiac operation. Zhonghua wei zhong bing ji jiu yi xue 2016, 28(5):391-395.

32. Berkenstadt $\mathrm{H}$, Margalit N, Hadani M, Friedman Z, Segal E, Villa Y, Perel A: Stroke volume variation as a predictor of fluid responsiveness in patients undergoing brain surgery. Anesthesia and analgesia 2001, 92(4):984-989.

33. Feissel M, Michard F, Mangin I, Ruyer O, Faller JP, Teboul JL: Respiratory changes in aortic blood velocity as an indicator of fluid responsiveness in ventilated patients with septic shock. Chest 2001, 119(3):867-873.

34. Keller G, Cassar E, Desebbe $\mathrm{O}$, Lehot JJ, Cannesson M: Ability of pleth variability index to detect hemodynamic changes induced by passive leg raising in spontaneously breathing volunteers. Critical care (London, England) 2008, 12(2):R37.

35. Michard F: Changes in arterial pressure during mechanical ventilation. Anesthesiology 2005, 103(2):419-428; quiz 449-415.

36. Cannesson M, Delannoy B, Morand A, Rosamel P, Attof $Y$, Bastien $O$, Lehot JJ: Does the Pleth variability index indicate the respiratory-induced variation in the plethysmogram and arterial pressure waveforms? Anesthesia and analgesia 2008, 106(4):1189-1194, table of contents.

37. Cannesson M, Desebbe O, Rosamel P, Delannoy B, Robin J, Bastien 0 , Lehot JJ: Pleth variability index to monitor the respiratory variations in the pulse oximeter plethysmographic waveform amplitude and predict fluid responsiveness in the operating theatre. British journal of anaesthesia 2008, 101(2):200-206.

38. Marik PE, Cavallazzi R, Vasu T, Hirani A: Dynamic changes in arterial waveform derived variables and fluid responsiveness in mechanically ventilated patients: a systematic review of the literature. Critical care medicine 2009, 37(9):2642-2647.

39. Choi DY, Kwak HJ, Park HY, Kim YB, Choi CH, Lee JY: Respiratory variation in aortic blood flow velocity as a predictor of fluid responsiveness in children after repair of ventricular septal defect. Pediatric cardiology 2010, 31(8):1166-1170.

40. Monnet X, Dres M, Ferre A, Le Teuff G, Jozwiak M, Bleibtreu A, Le Deley MC, Chemla D, Richard C, Teboul JL: Prediction of fluid responsiveness by a continuous non-invasive assessment of arterial pressure in critically ill patients: comparison with four other dynamic indices. British journal of anaesthesia 2012, 109(3):330-338.

41. Baloch K, Rehman Memon A, Ikhlaq U, Umair M, Ansari MI, Abubaker J, Salahuddin N: Assessing the Utility of End-Tidal Carbon Dioxide as a Marker for Fluid Responsiveness in Cardiogenic Shock. Cureus 2021, 13(2):e13164.

42. Guinot PG, Godart J, de Broca B, Bernard E, Lorne E, Dupont $\mathrm{H}$ : End-expiratory occlusion manoeuvre does not accurately predict fluid responsiveness in the operating theatre. British journal of anaesthesia 2014, 112(6):1050-1054.

43. Zhao H, Wang X, Liu D: The role of end-tidal carbon dioxide partial pressure in fluid responsiveness assessment in septic shock patient. Zhonghua nei ke za zhi 2014, 53(5):359-362.

44. Cavallaro F, Sandroni C, Marano C, La Torre G, Mannocci A, De Waure C, Bello G, Maviglia R, Antonelli M: Diagnostic accuracy of passive leg raising for prediction of fluid responsiveness in adults: systematic review and meta-analysis of clinical studies. Intensive care medicine 2010, 36(9):1475-1483.

45. Cherpanath TG, Hirsch A, Geerts BF, Lagrand WK, Leeflang MM, Schultz MJ, Groeneveld AB: Predicting Fluid Responsiveness by Passive Leg Raising: A Systematic Review and Meta-Analysis of 23 Clinical Trials. Critical care medicine 2016, 44(5):981-991.

46. Laher AE, Watermeyer MJ, Buchanan SK, Dippenaar N, Simo NCT, Motara F, Moolla M: A review of hemodynamic monitoring techniques, methods and devices for the emergency physician. The American journal of emergency medicine 2017, 35(9):1335-1347.

\section{Figures}




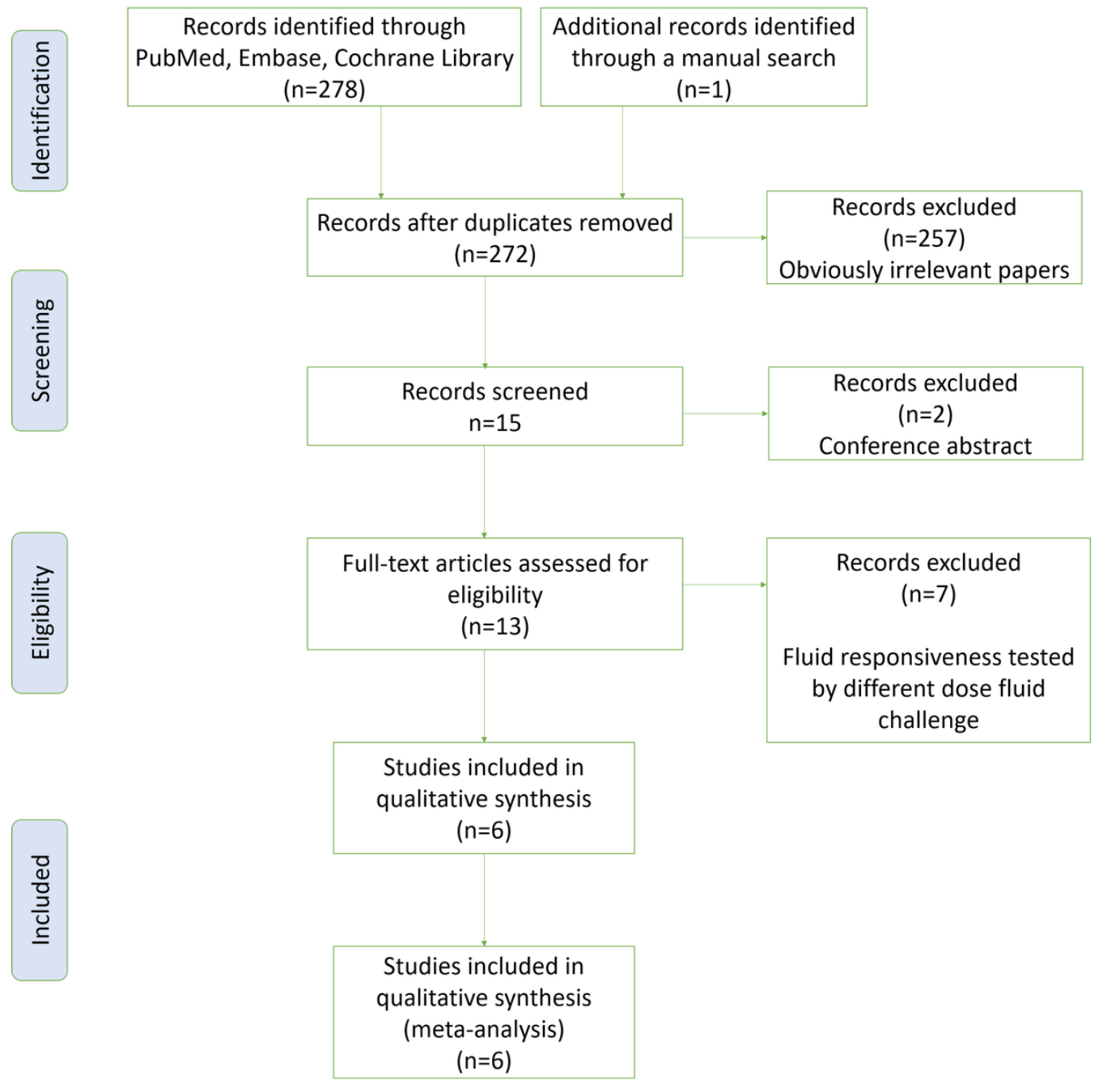

Figure 1

Flow diagram of identification of studies. 

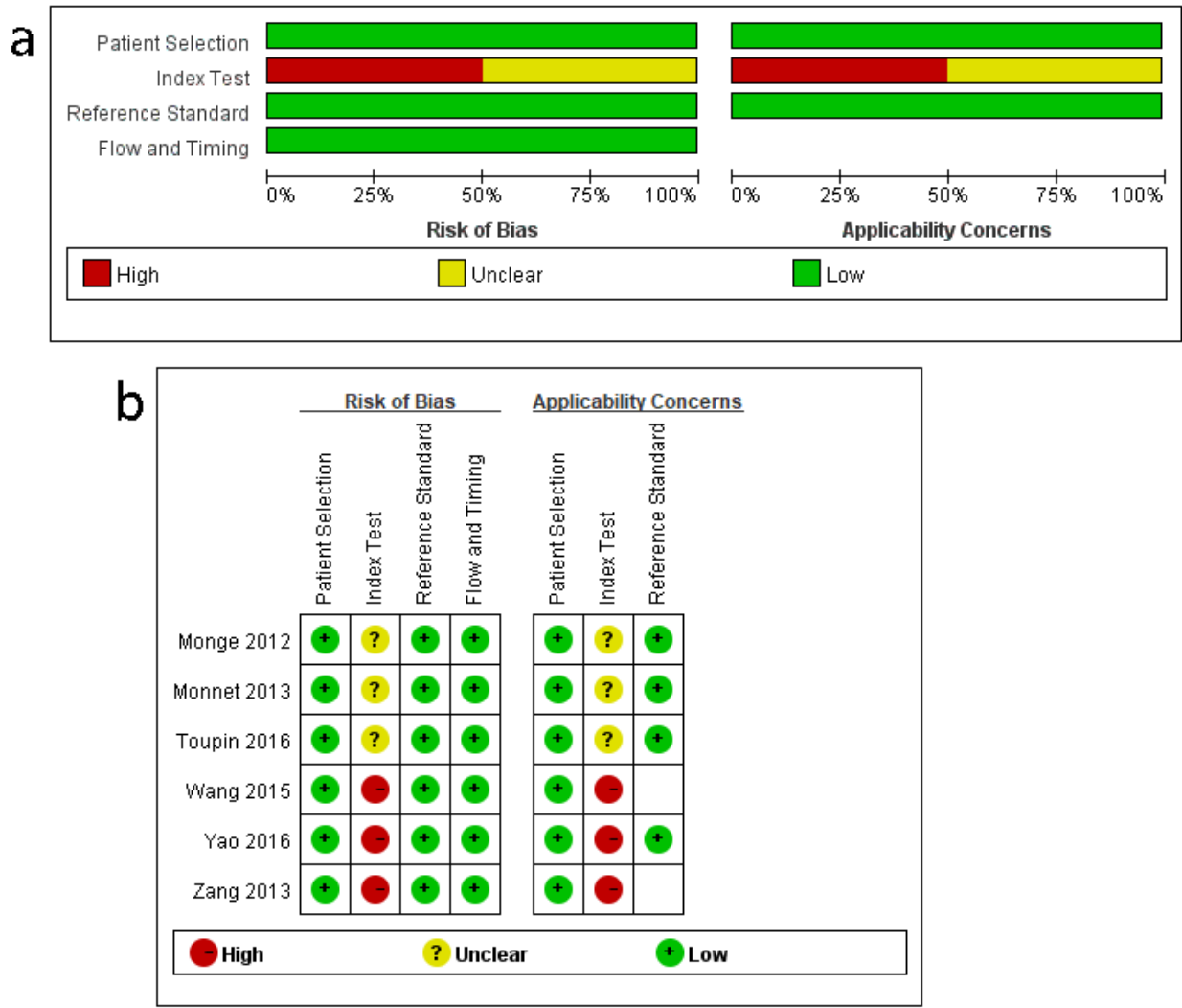

\section{Figure 2}

Risk of bias and applicability concerns for the studies included in the meta-analysis. (a) Risk-of-bias graph; (b) Risk-of-bias summary.

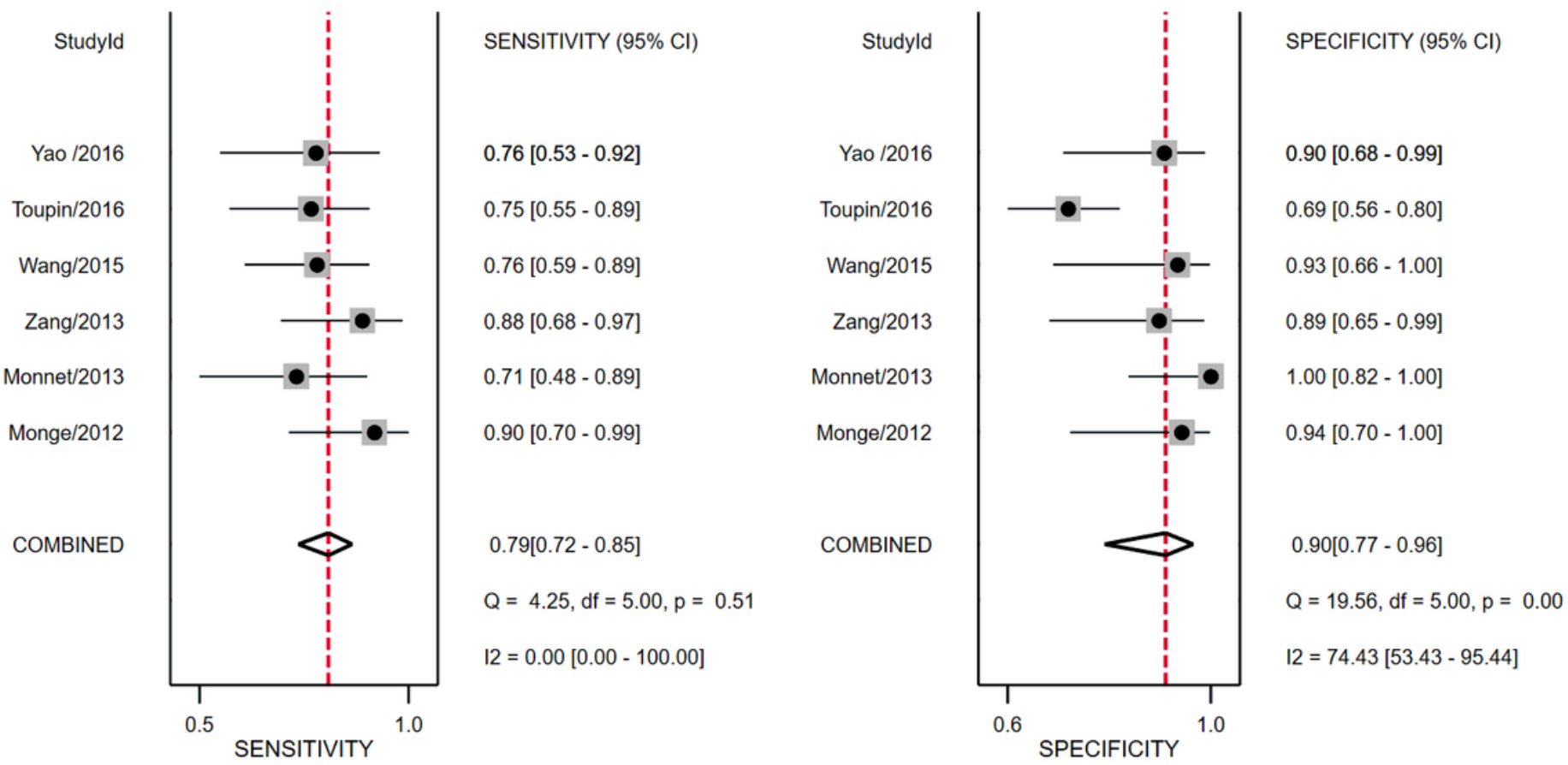

Figure 3

Forest plots of the pooled sensitivity and specificity. Each solid square represents an individual study. Error bars represent $95 \% \mathrm{Cl}$. Diamond indicates the pooled sensitivity and specificity for all of the studies. 


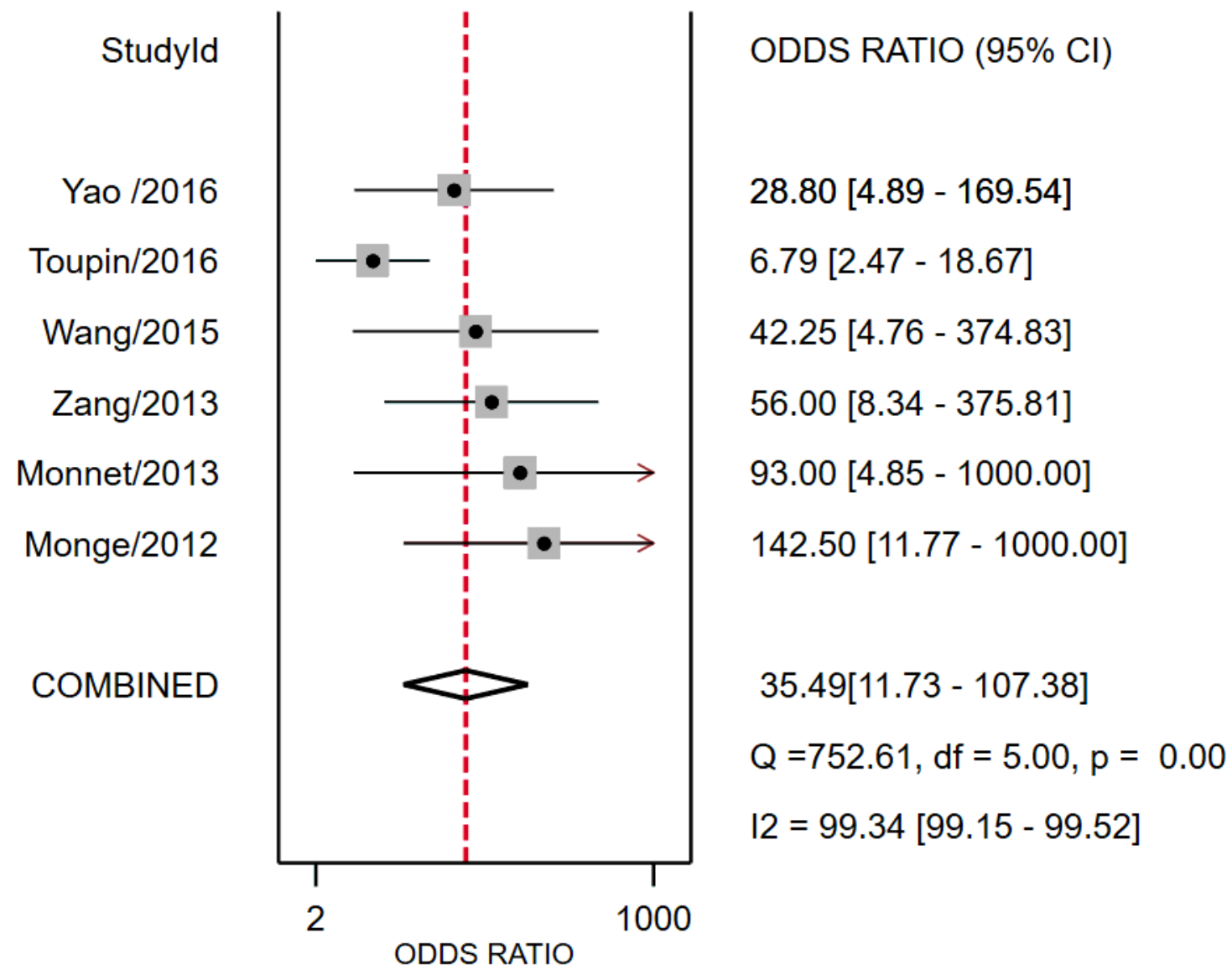

Figure 4

Forest plots of the pooled diagnostic odds ratio. Each solid square represents an individual study. Error bars represent $95 \% \mathrm{Cl}$. Diamond indicates the pooled diagnostic odds ratio for all of the studies. 


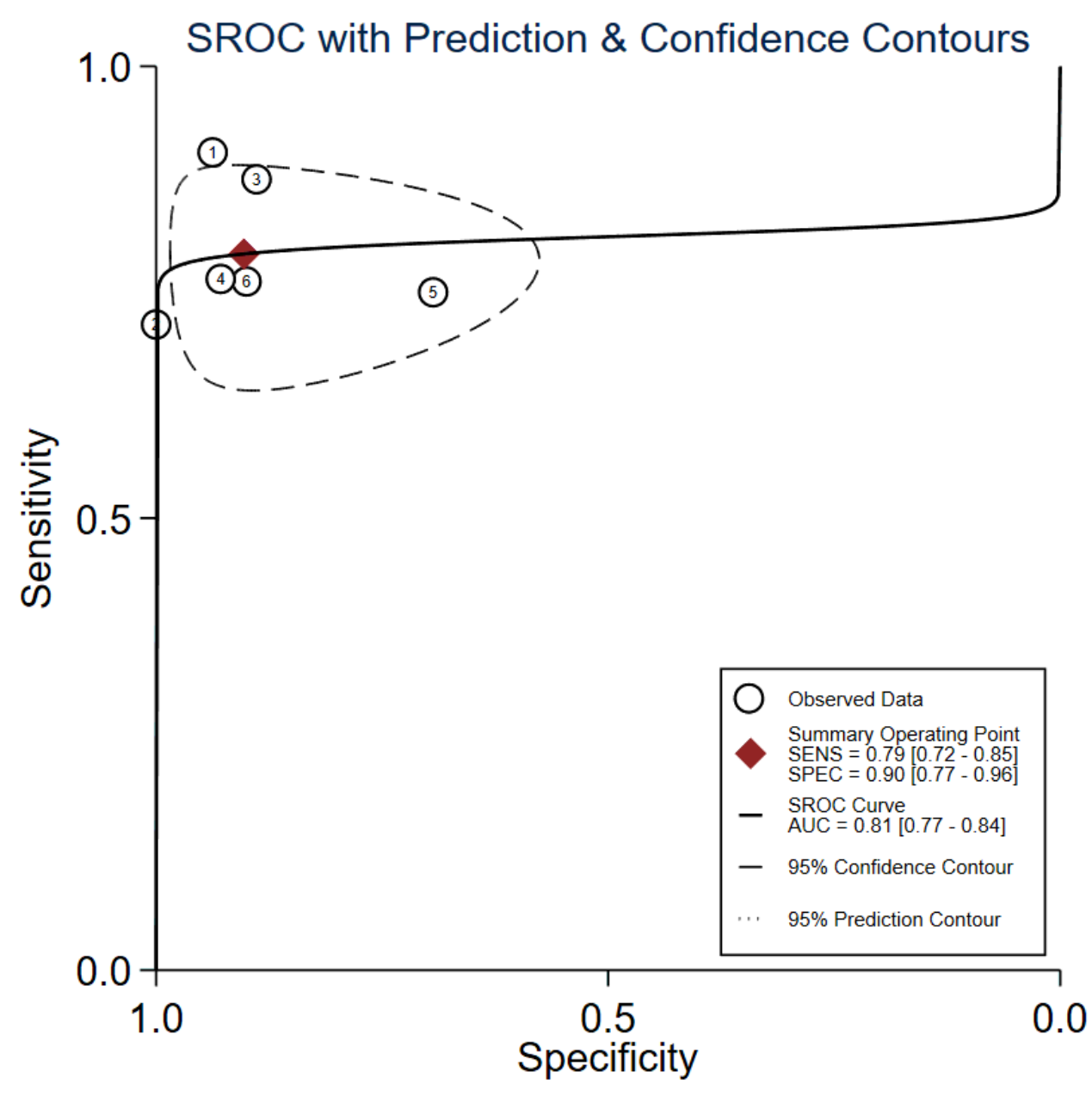

Figure 5

SROC curve of variation of end-tidal carbon dioxide for predicting fluid responsiveness. Each circle represents individual study estimates. The diamond is the summary point representing the average sensitivity and specificity estimates. The ellipses around this summary point are the $95 \%$ confidence region(dashed line) and the 95\% prediction region (dotted line). The cutoff value of included studies: (1) Monge/2012[16]:5\%; (2)Monnet/2013[15]: 5\%; (3)Zang/2013[28]:5\%; (4) Wang/2015 [29]: 5\%; (5) Toupin/2016 [30]:2mmHg; (6) Yao /2016 [31]: 5.8\%. 
Univariable Meta-regression \& Subgroup Analyses
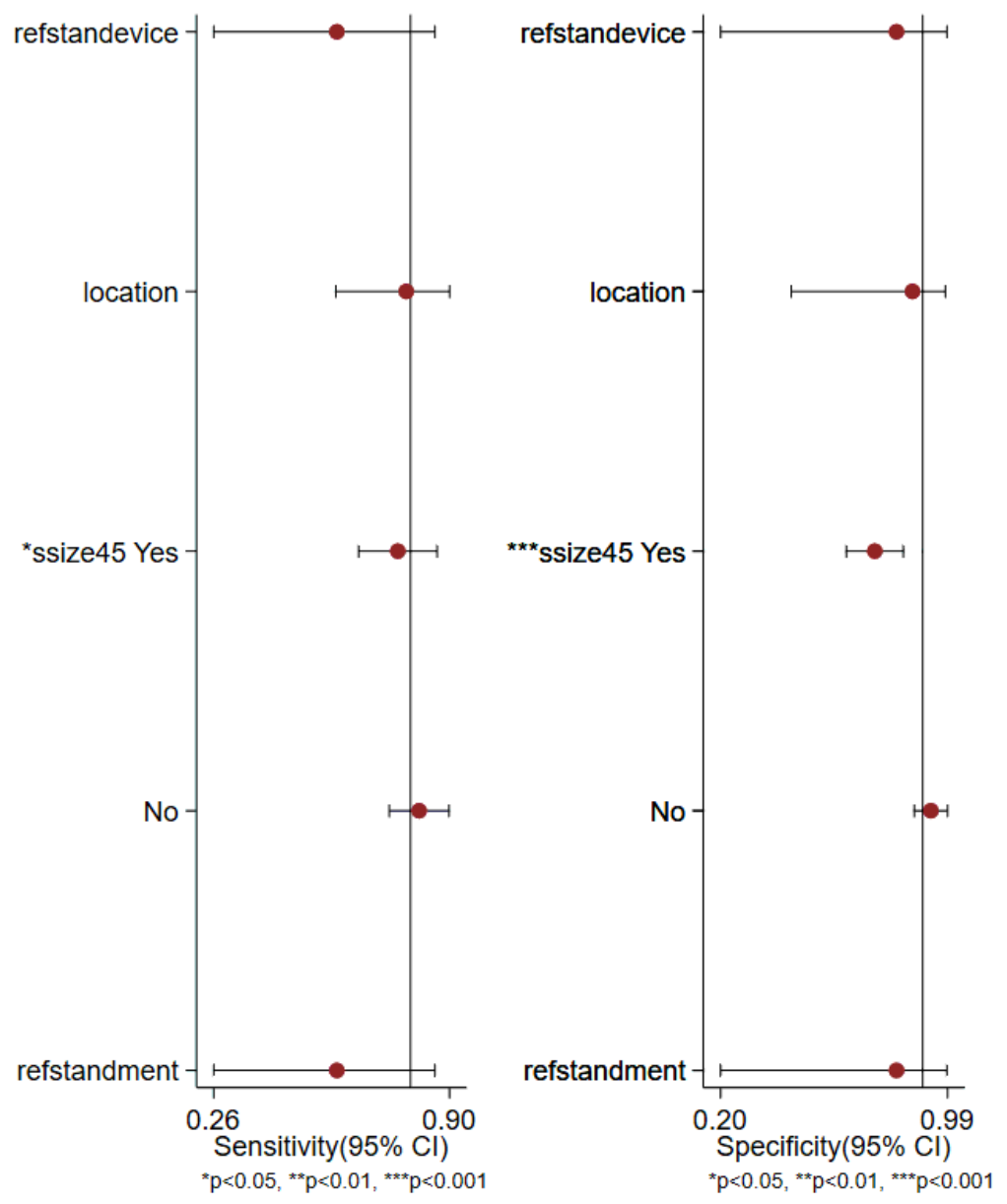

\section{Figure 6}

Graphs for Meta-regression analysis. $\mathrm{Cl}$ = confidence interval. Meta-regression was performed by refstandevice (TEE vs. PiCCO),location (China vs. countries other than China),ssize45 ( $₫ 45$ vs.<45);refstandment (CO vs. $\mathrm{Cl}$ ). 


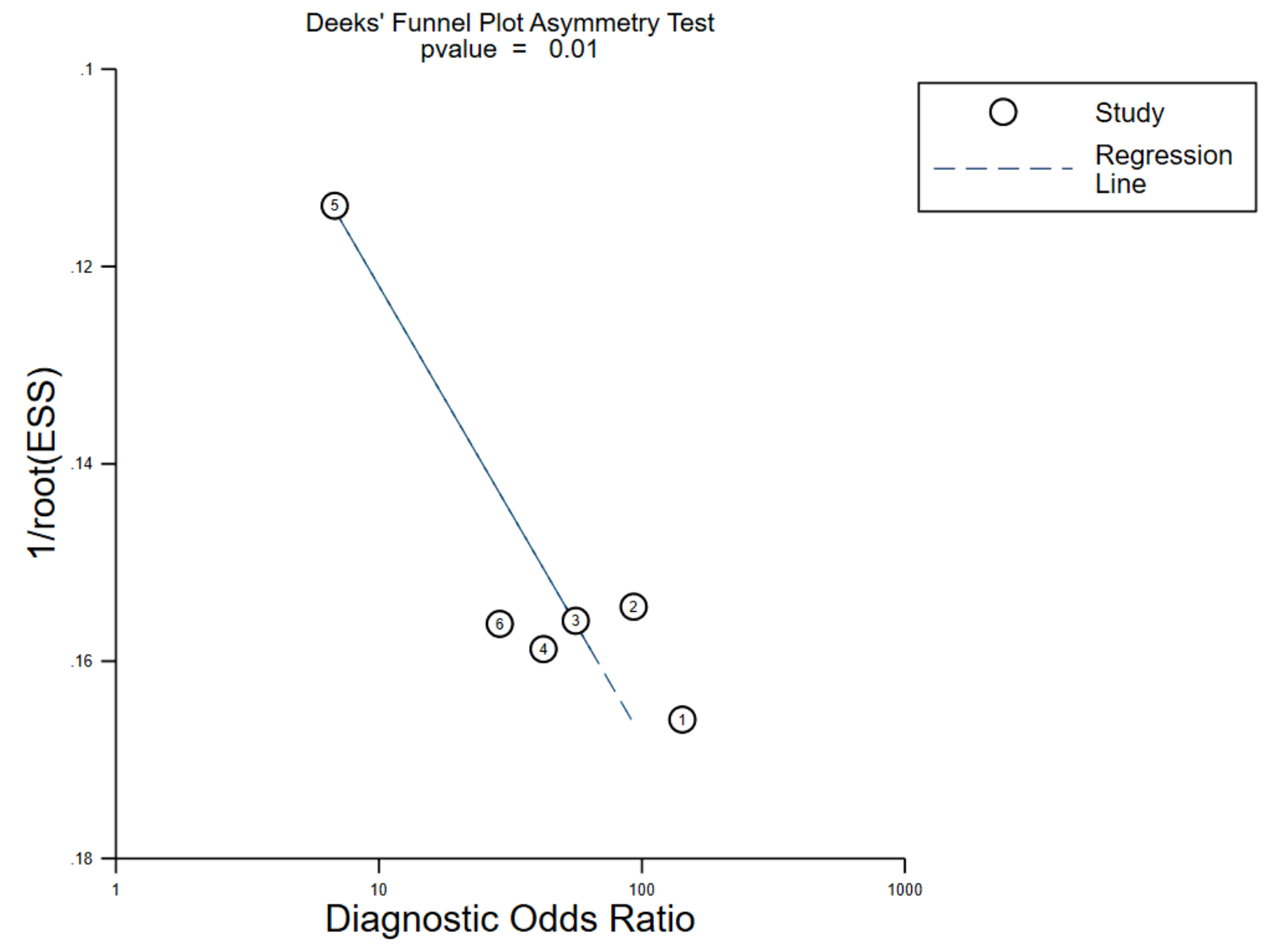

Figure 7

Deeks' funnel plot of publication bias among studies. ESS = effective sample size. Numbers 1 to 6 represent the study arms (Monge/2012, Monnet/2013,Zang/2013,Wang/2015 ,Toupin/2016,Yao /2016). 


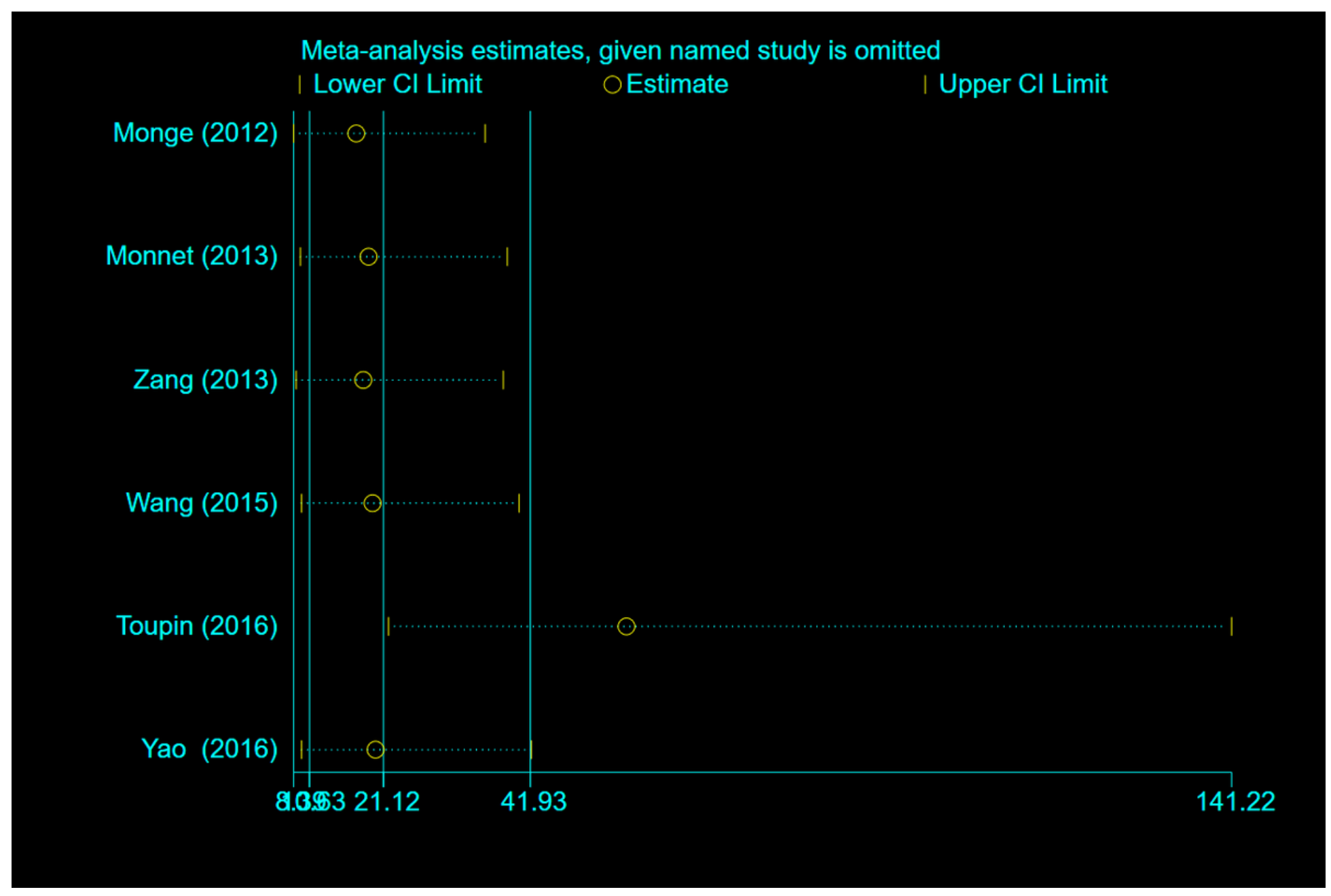

Figure 8

Graphs for sensitivity analysis.

\section{Supplementary Files}

This is a list of supplementary files associated with this preprint. Click to download.

- PRISMAChecklist.doc 